smoking mothers are thinner and their babies are thinner too, but even accepting the limitations of correction for this effect, the growth-retarding effect of smoking on the fetus is hardly affected by this correction. A similar conclusion was derived from Cardiff Birth Survey data, in a community study on smoking and pregnancy. ${ }^{8}$ We postulate from our data and from other data already reported, that the growth-retarding effect of maternal smoking on the infant is a complex multifactorial one.

It is clear that efforts should be intensified to prevent expectant mothers smoking as there is evidence that there may be long-term effects on children's learning ability later in childhood, ${ }^{9}$ and we and Davies et al. ${ }^{6}$ have found a reduction in head circumference in the infants of smoking mothers.

We thank Dr E R Verrier Jones, Miss Joan Andrews, and $\mathrm{Mr} \mathrm{K}$ Johannsen, for allowing us to study their patients, and Miss $\mathbf{S}$ James for secretarial assistance.

\footnotetext{
References

1 Simpson W J. A preliminary report on cigarette smoking and the incidence of prematurity. Am J Obstet Gynecol 1957; 73: 808-15.

2 Rush D. Examination of the relationship between
}

birthweight, cigarette smoking during pregnancy, and maternal weight gain. J Obstet Gynaecol Br Commonw 1974; 81 : 746-52.

3 Cole P V, Hawkins L H, Roberts D. Smoking during pregnancy and its effects on the fetus. J Obstet Gynaecol Br Commonw 1972; 79: 782-7.

4 Parkin J M, Hey E N, Clowes J S. Rapid assessment of gestational age at birth. Arch Dis Child 1976; 51: 259-63.

5 Oakley J R, Parsons R J, Whitelaw A G L. Standards for skinfold thickness in British newborn infants. Arch Dis Child 1977; 52: 287-90.

6 Davies D P, Gray O P, Ellwood P C, Abernethy M. Cigarette smoking in pregnancy: associations with maternal weight gain and fetal growth. Lancet 1976; i: 385-7.

7 Meyer M B. How does maternal smoking affect birthweight and maternal weight gain? Am J Obstet Gynecol $1978 ; 131$ : 888-93.

8 Andrews J, McGarry J M. A community study of smoking in pregnancy. J Obstet Gynaecol Br Commonw 1972; 79: 1057-73.

9 Fogelman K. Smoking in pregnancy and subsequent development of the child. Child Care Health Dev 1980; 6: $233-49$.

Correspondence to $\operatorname{Dr}$ A R J Bosley, Department of Paediatrics, North Devon District Hospital, Raleigh Park, Barnstaple, North Devon EX31 4JB.

Received 12 March 1981

\title{
Bronchodilator effect of inhaled ipratropium bromide in wheezy toddlers
}

\author{
I G C HODGES, R C GROGGINS, A D MILNER, AND G M STOKES \\ Department of Child Health, Queen's Medical Centre, Nottingham
}

\begin{abstract}
SUMMARY Airways obstruction was measured before and after inhaled ipratropium bromide in 32 wheezy children aged between 3 months and 2 years 8 months using a total body plethysmograph and a modification of the forced oscillation technique. No relationship was found between age and incidence of response. About $40 \%$ of those under age 18 months had an improvement in lung function. This form of treatment may have a place in the management of the wheezy infant too young to respond to beta-2 stimulants.
\end{abstract}

Children under age 20 months who wheeze repeatedly still present a problem in management, as beta-2 adrenergic stimulant therapy is rarely effective. In an earlier study Lenney and Milner ${ }^{1}$ showed that salbutamol was an effective bronchodilator agent in wheezy children over age 20 months if administered via a nebuliser, but not in children under age 18 months. Other studies in children under age 12 months have failed to show any improvement in lung function after isoprenaline, ${ }^{2}$ salbutamol, ${ }^{3}$ phenylephrine, or adrenaline ${ }^{4}$ inhalation.

Ipratropium bromide, an anticholinergic drug, has been shown to be an effective bronchodilator agent in children over age 3 years when administered via a nebuliser. ${ }^{5}$ The degree of bronchodilatation was equal to that produced by nebulised salbutamol. The main effect of ipratropium bromide is thought to be in the large airways, mediated by blocking cholinergic receptors on bronchial smooth muscle. Its advantage over atropine by inhalation is that it has fewer side effects.

The aim of this study was to find out if wheezy children under age 3 years would respond to inhalation of ipratropium bromide and if so, would that response be age related. 


\section{Method}

Children under age 3 years who attended the hospital because of wheezing were entered into the trial. Each child was sedated with chloral hydrate 80 to $120 \mathrm{mg} / \mathrm{kg}$. When sedated the child was placed in a whole body plethysmograph incorporating a servo-controlled heating system to maintain the shutter assembly, rebreathing bag, and face mask at $36^{\circ} \mathrm{C}$. Airways resistance (RAw) and thoracic gas volume (TGV) were measured using a plethysmographic technique. ${ }^{6}$ Total respiratory resistance $\left(R_{T}\right)$ was measured using the forced oscillation technique. ${ }^{7}$ A pressure manometer connected to the inflated flange of the face mask ensured that the mask was applied to the face with the same amount of pressure during each measurement of $R_{T}$. Initial recordings of RAW, TGV, and $R_{T}$ were made and then each child was given $2 \mathrm{ml}$ of a solution containing $250 \mu \mathrm{g}$ ipratropium bromide through a Sandoz nebuliser driven by compressed air at a flow rate of 61 minutes. This dose of ipratropium bromide was chosen as it had produced an appreciable degree of bronchodilatation in children between ages 3 and 5 years in a previous study. ${ }^{5}$ RAw, TGV, and $R_{T}$ were then repeated 10 and 20 minutes after the inhalation. Children who remained asleep 30 minutes after the inhalation of ipratropium bromide were given $0.5 \mathrm{ml}$ salbutamol respirator solution $(0.5 \%)$ diluted in $1.5 \mathrm{ml}$ of water via a nebuliser. RAw, TGV, and $R_{T}$ were measured 5 minutes after the inhalation. Pulse rate was recorded before and after each treatment.

\section{Subjects}

Thirty-two children ( 23 boys and 9 girls) were studied. Their age at the time of the study ranged from 3 months to 2 years 8 months (mean age 13 months). Thirty of them had been admitted to hospital because of wheezing, and 2 children had been seen in the outpatients clinic with persistent wheezing but had not been admitted. Although most children were tested during their first attack of wheezing, 12 children subsequently have had at least 2 admissions to hospital with wheezing, and 14 further children have been seen in the outpatient clinic with recurrent wheezing. Of the remaining 6 children one has had no further chest problems but has developed eczema, and one has had numerous visits to her general practitioner with coughs and colds, and 4 patients could not be traced. Eleven children had eczema and 14 had an immediate family history of asthma. Twenty-seven children were studied using both the total body plethysmograph and forced oscillation technique. Owing to technical problems 2 children were studied using only the total body
Table Number of children in each age group responding to ipratropium with a greater than $15 \%$ improvement in Raw, $S G \mathrm{AW}, R_{\mathrm{T}}$, and both $R \mathrm{AW}$ and $R_{\mathrm{T}}$ combined

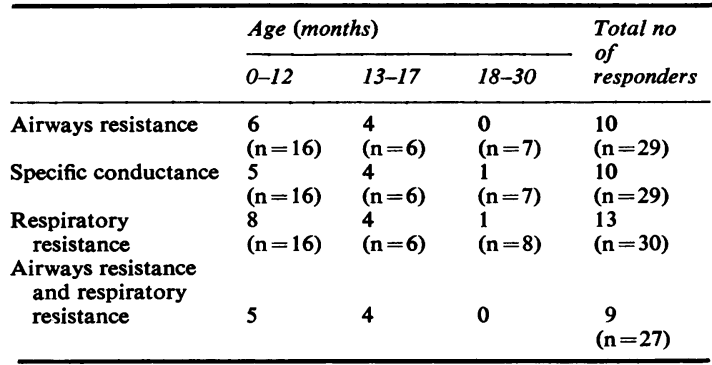

plethysmograph, and a further 3 using only the forced oscillation technique.

All the children were wheezing clinically at the time of the study. Ethical committee approval was obtained for the study and fully informed parental consent was given for each child.

\section{Results}

As there were no normal data available for $\mathbf{R}_{\mathrm{T}}$ for the age range studied and no data on RAw using a heated shutter system for healthy children between ages 1 and 3 years, all the results have been expressed as a percentage change from initial. After inhaled ipratropium bromide 13 children showed a fall in $R_{T}$ greater than $15 \%, 8$ of whom were under age 1 year (Figure). Ten children showed a fall in RAw greater than $15 \%, 6$ of whom were under age 1 year. Twenty-eight of 29 had TGVs above the mean predicted value for height. ${ }^{8}$ On average the TGV was $175 \%$ of the predicted level, with a range of 73 to $326 \%$. One child aged 21 months improved her TGV by $23 \%$ after nebulised ipratropium bromide. All the other children had changes less than $15 \%$. There was a mean increase in TGV of $4.5 \%$ at 20 minutes.

Expressing the plethysmograph results in terms of specific conductance (SGAw) 10 children showed a greater than $15 \%$ improvement after ipratropium bromide, 5 of whom were under age 1 year (Figure).

The condition of 2 children aged 21 and 22 months deteriorated both clinically and on lung function testing after inhaled ipratropium bromide with increases in $R_{T}$ of $32 \%$ and $24 \%$. The former child remained asleep long enough for assessment of response to inhaled salbutamol. His $\mathbf{R}_{\mathbf{T}}$ then fell by $54 \%$ and his clinical state also improved appreciably.

Fourteen children were given nebulised salbutamol 30 minutes after the inhalation of ipratropium bromide. None of the 10 children under 18 months responded to inhaled salbutamol. Of the 4 children 


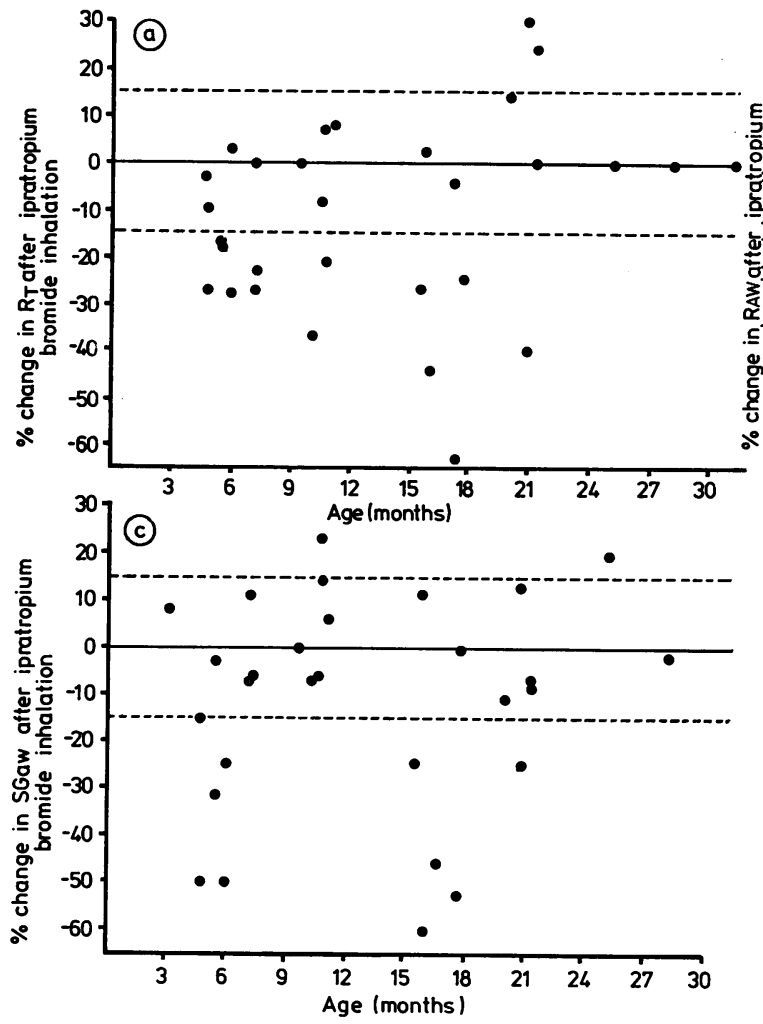

aged between 20 and 25 months who did not respond to ipratropium bromide only 2 responded to nebulised salbutamol with a greater than $15 \%$ improvement in measurement of lung function, the remaining 2 showing no changes in lung function or clinical condition. Both these children later responded clinically to inhaled salbutamol between 18 and 24 hours after starting treatment with systemic steroids.

There was no increase in heart rate after inhaled ipratropium bromide, but the mean increase after inhaled salbutamol was 25 beats per minute (range 10-40).

\section{Discussion}

These results show that in some wheezy children under age 18 months ipratropium bromide is an effective bronchodilator. We were unable to predict from the clinical state of the child or from initial lung function tests which children would respond. In all the children who did respond there was little change in the TGV apart from one child in whom it fell by $23 \%$, suggesting that the main site of action for

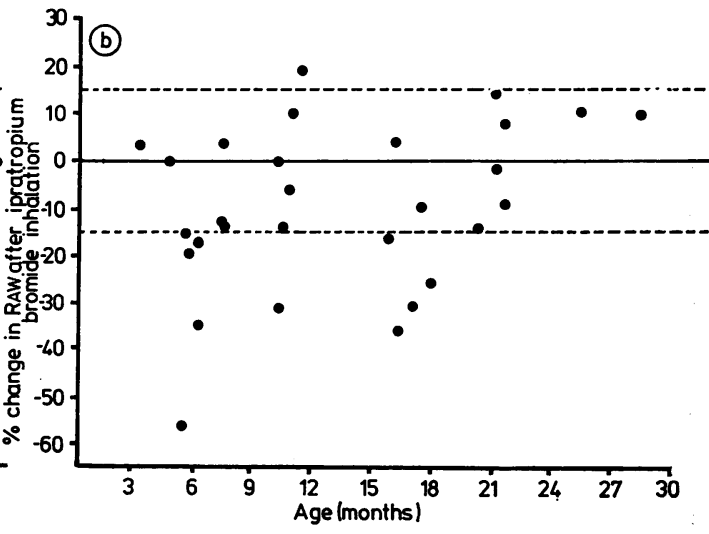

Figure Percentage change for (a) $R_{\mathrm{T}}$, (b) $R_{\mathrm{AW}}$, and (c) $S G$ AW 20 minutes after inhaling $a$ solution containing $25 \mu \mathrm{g}$ ipratropium bromide. Zero line represents the initial value and each plot an individual child. Plots below the zero line represent improvement and those above deterioration. ipratropium bromide is not in the small airways. It is not clear why some children respond to ipratropium bromide while others do not. One possibility is that the distribution of obstruction in the small and large airways differed between those who improved and those who did not, the children with predominantly large airways obstruction responding to inhaled ipratropium bromide.

It may be that ipratropium bromide merely caused a decrease in secretion in view of its anticholinergic nature which in turn reduced large airways resistance but not oedema in the small airways. This is unlikely as improvement mainly occurred within 10 minutes of the inhalation. Although no placebo inhalations were given, previous studies ${ }^{4}$ failed to identify any child in this age range who derived benefit from placebo.

It is concluded that nebulised ipratropium bromide is effective in relieving airways obstruction in wheezy children as young as 5 months and that the response is not age related between 5 and 30 months. We were unable to determine which children will respond on clinical grounds or on the lung function parameters used in this study. 
732 Hodges, Groggins, Milner, and Stokes

Financial support was provided by the Asthma Research Council and Boehringer Ingelheim.

\section{References}

1 Lenney W, Milner A D. At what age do bronchodilator drugs work? Arch Dis Child 1978; 53: 532-5.

2 Phelan P D, Williams H E. Studies of respiratory function in infants with recurrent asthmatic bronchitis. Aust Paediatr J 1969; 5: 187-96.

3 Rutter N, Milner A D, Hiller E J. Effect of bronchodilators on respiratory resistance in infants and young children with bronchiolitis and wheezy bronchitis. Arch Dis Child 1975; 50: 719-22.

4 Lenney W, Milner A D. Alpha and beta adrenergic stimulants in bronchiolitis and wheezy bronchitis in children under eighteen months of age. Arch Dis Child 1978; 53: 707-9.

5 Groggins R C, Milner A D, Stokes G M. Bronchodilator effects of clemastine, ipratropium bromide, and salbutamol in preschool children with asthma. Arch Dis Child 1981; 56: $342-4$.

${ }^{6}$ Stocks J, Levy N M, Godfrey S. A new apparatus for the accurate measurement of airways resistance in infancy. J Appl Physiol 1977; 43: 155-9.

7 Cogswell J J. Forced oscillation technique for determination of resistance to breathing in children. Arch Dis Child 1973; 48: 259-66.

8 Doershuk C F, Downs T D, Matthews L W, Lough M D. A method for ventilatory measurements in subjects one month to five years of age. Normal results and observations in disease. Pediatr Res 1970; 4: 165-74.

Correspondence to Professor A D Milner, Department of Child Health, E Floor, East Block, University Hospital, Queen's Medical Centre, Clifton Boulevard, Nottingham NG7 2UH.

Received 12 March 1981 